\title{
DEPRESSION'S WAY OF EXPRESSION IN THE CASE OF A PARANOID-SCHIZOTYPAL PERSONALITY STRUCTURE
}

Simona Trifu ${ }^{1}$, Alexandru Gherman ${ }^{2}$, Alexandra Militaru², Ilinca Vlaicu, Raisa ${ }^{2}$, Constantinescu-Coban ${ }^{3}$ and Florin Mititelu ${ }^{4}$

\footnotetext{
1 "Carol Davila” University of Medicine and Pharmacy, Bucharest, Romania

${ }^{2}$ Faculty of Psychology and Educational Science, University of Bucharest, Romania

Romanian Society of Psychoanalysis, Bucharest, Romania

4Alex Obregia” Clinical Hospital for Psychiatry, Bucharest, Romania
}
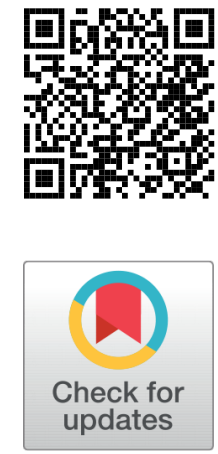

Received 11 June 2021

Accepted 20 June 2021

Published 30 June 2021

Corresponding Author

Simona Trifu, simona.trifu@umfcd

.ro

DOI $10.29121 /$

granthaalayah.v9.i6.2021.3982

Funding: This research received no specific grant from any funding agency in the public, commercial, or not-for-profit sectors.

Copyright: (C) 2021 The Author(s). This is an open access article distributed under the terms of the Creative Commons Attribution License, which permits unrestricted use, distribution, and reproduction in any medium, provided the original author and source are credited.

\section{ABSTRACT}

Motivation: A psychiatric patient should be looked at in the longitudinal dynamics of their life because it is possible that during youth, mental suffering has a certain tone to it, which is later erased, transformed or moved, through a greater or lesser contact with the ideas or the affect.

Objective: We want to present the life history and intrapsychic dynamics of a subject whose first episode of mental illness of a depressive nature was around the age of 20 , and to emphasize how over the years, this nature has faded. Currently, there is an absence of connection between the symptoms and the possible causalities.

Material and methods: psychiatric and psychoanalytic interviews in dynamics, analysis of the life map, interpretations, the symptom's evolution under medication, social support, identification of positive and negative prognostic factors, differential diagnoses, performing the diagnostic tree.

Results: The patient presented a first depressive episode in youth with a trigger related to an important emotional relationship; the episode overlapping with childhood difficulties (a father with a penal past, absence of parental Superego, attempts to build a shield through divinity). There follows a period of well-being, over which, about ten years ago, a hypochondriac pathology occurs, which associates the significant change of behaviour in a bizarre psychotic sense, with homelessness, delusional interpretation and completed with suicide attempt, so that the last episode is predominantly psychotic, but with a mystical and guilt theme and sin, with important behavioural changes, which also highlights the paranoid personality background of the person in question.

Conclusion: The personality structure along with social functioning are important milestones of clinical evolution, beyond the main diagnosis of axis I, which in this case remained of recurrent depressive disorder, major depressive episode with psychotic phenomena, with the first two differential diagnoses: Bipolar affective disorder or Affective schizophrenia - depressive episode 
Keywords: Paranoid Premorbid Personality, Impaired Social Functioning, Productive Phenomenology, Xenopathic Control Of Ideation, Behaviour

\section{INTRODUCTION}

We are presenting a male patient, aged 39 , with a psychiatric history recorded in the Psychiatric Hospital at the age of approximately 20 years, the diagnosis being that of recurrent depressive disorder, severe depressive episode with psychotic elements. After this episode, the man had no treatment between 7-10 years in which he no longer faced psychiatric problems.

As a life history, the man comes from a biparental family of ordinary people, the father with a history of incarceration, and a sister recently diagnosed with skin cancer (malignant melanoma) at the time of the clinical interview. The man also has feelings of inferiority towards his parents. The lack of the paternal image from childhood due to the imprisonment of the father led to the search for an authority, a parent to take care of him; he found this authority at the church. At the age of 6 , he asked his neighbour ("Bogdănel's mother") to take him to church. Thus, the patient created a rigid, severe self. Does not smoke, does not consume alcohol or drugs. His first girlfriend had two miscarriages after having intercourse when he was 18 years old.

Academically, the patient graduated from the Faculty of Tourism Economics, University of Bucharest, after attending the courses of the Faculty of Industrial Chemistry for a year. The baccalaureate exam was graduated with an average of 6.99.

From the point of view of professional history, the patient was employed in a store selling Puma sports shoes where he started as a store salesman and advanced to assistant store manager. He later resigned to set up his own competing footwear company. The man was forced to pay compensation to the former employers due to the non-compete clause in the signed employment contract.

In Denmark he was hired to provide cleaning services at educational institutions.

At the time of the current episode, he had been studying for a master's degree in Denmark for about 5 years, at the master's degree in "Management, Marketing \& Sport", and is in a relationship with a Romanian woman with a good social position. He does not work, feels vulnerable and limits his search and application to new jobs for fear of discovering the history of the conflict with the former boss of the sports shoe store, a fear based on incorrectness and guilt.

work.

\section{MATERIALS AND METHODS}

In this article, we included details from psychiatric evaluation, psychiatric interview, psychodynamic interviews, and psychodynamic interpretations. The patient has benefited from psychiatric and psychological monitoring of the daily progression 
under treatment.

\section{RESULTS AND DISCUSSIONS}

\subsection{CLINICAL DESCRIPTION OF THE CASE}

He describes the beginning of the current episode, saying that one morning his own conscience told him to throw the key (from the house) into the grass if he really believed in God. He was then led to a church where he entered naked and prayed, and on his return, he was guided back by conscience and found the key in the grass where he had thrown it. The speech curls up possible auditory hallucinations that the patient denies by saying that these are very close to what he normally thinks. After telling a Romanian friend about what happened, the latter decided to go and bring him to a specialist back in Romania.

The man declares that for three years now he has not had a personal and sexual life due to the faith and the observance of the rigors of the Christian-Orthodox religion, wanting to get closer to God. He believes that this has led to his somatic problems: lumbar, thoracic, cervical hernia. At the same time, the patient mentions that he presents somatic pains that have decreased in intensity after following the treatment prescribed by the current psychiatrist with Romparkin and Diazepam.

This episode may symbolize a validation of the forgiveness of sins committed in youth, namely, if God allows the key to be found in the grass where it was thrown, it means that it accepts it. Thus, one can notice an obsession to become clean again, to be forgiven and accepted, coming from the area of severely developed super-self and a less visible compulsivity with compulsions by denial related to the area of calming anxiety given by severe spirituality accomplished by depriving oneself of activities that are framed in the area of sin Freud et al. (2009)

He talks about himself, mentioning his concern for the safety of those close to him and his desire to sacrifice ("to let go of yourself", "to be proud of the good of others"). The man said he received a scholarship from the Danish state on the condition that he lives in Denmark. Because he had gone to Romania for a few months, he denounced himself, and with the help of his girlfriend he managed to pay the fine of tens of thousands of euros to the Danish state. The patient's story shows daring gestures based on his desire for justice and guilt.

The patient's explanation for this unexpected episode is the lack of vitamins for 6-7 months due to treatment for late-onset infection and dietary restrictions followed due to worsening of the condition. The patient presents a disorganized speech, observing difficulties of concentration and lax logical associations. There is also an inability to couple emotions with actions.

In the case of the first episode and the first psychiatric hospitalization done in 2009 , at the age of 28, the patient reports the follow-up of a treatment for colds, found through the Internet, namely lime tea and ultraviolet light bulb. After buying and placing the lamp and the ultraviolet light bulb on the bed, he started the light 
treatment, sitting with his mother and sister for 10 minutes. After 10 minutes, the women began to feel pain and stopped treatment, and due to the diffused light, the man fell asleep under the light bulb and woke up in the morning, at 7 o'clock, with swollen eyes, eyelids closed shut and dryness on the upper eyelid. The patient had to hide his suffering from his family because his father is a "tough person who does not understand the suffering of others."

As the summer season approached and the light increased in intensity, he felt more and more burning on his skin and eye area. He took action, bought glasses, blinds and wrote a message to NASA. Moreover, he states that he has "mosquitoes on his retina" left over from then. Following a dermatological and ophthalmological consultation, no solutions were found to the man's suffering.

The unconventional healing solution, along with offering magical explanations, highlights the characteristics of a schizotypal personality. At the same time, there is a poor test of reality and a delusional interpretation with changing behaviour. Trifu (2016)

Regarding the nictemeral rhythm, the patient has insomnia due to mental suffering, which is why he went to a psychiatric consultation after not being able to sleep at all for 5 days; he was prescribed pills.

Subsequently, the man took 15 of the pills prescribed for insomnia and fell asleep in the park because he wanted to "sleep as much as possible to get rid of this suffering." The next day, he woke up at 6 o'clock and went to the Emergency Hospital where he was referred to the Psychiatric Hospital and admitted.

When the patient was asked directly if he realized that he had a disorganized speech in which he often jumped from one idea to another, he agreed that this time of expression is part of the sales activity where there is a need to express many things in a short amount of time and for this reason his mind jumps easily from one thing to another.

Currently, 2 years after the exposed episode, the patient is part of a psychotherapeutic process and a psychiatric treatment, going in for check-ups every 2 weeks.

\subsection{THEORETICAL PERSPECTIVE OF THE CASE}

The criteria in the DSM-5 for Short-Term Recurrent Depression are as follows:

The concomitant presence of a depressive mood and at least four other symptoms of depression for 2-13 days, at least once a month (unrelated to the menstrual cycle), at least 12 consecutive months, in a person whose clinical profile does not or has never met the criteria for another depressive or bipolar disorder and does not currently meet the criteria for any active or residual psychotic disorder.

The criteria in the DSM-5 for Major Depression, looking at the symptoms of depression, are as follows:

A. Five (or more) of the following symptoms were present during the same 2-week period and represent a change from previous level of functioning; at least one of the symptoms is either (1) depressive mood or (2) loss of interest or pleasure. 
1. Depressed mood most of the day, almost every day, either indicated by personal narration (e.g., feelings of sadness or inner emptiness, lack of hope), or observed by other people (e.g., seems sad). (Note: In children and adolescents, the mood may be irritable.)

2. Marked decrease in interest or pleasure in all or almost all activities, most of the day, almost every day (indicated either by personal narration or observed by other people).

3. Significant involuntary weight loss or weight gain (e.g., a change of more than $5 \%$ in body weight in a month), or decreased or increased appetite almost daily. (Note: In children, the inability to reach the expected weight is considered.)

4. Insomnia or hypersomnia almost every day

5. Agitation or psychomotor slowness almost every day (observed by other people, not just subjective feelings of restlessness or slowness).

6. Fatigue or lack of energy almost every day

7. Feelings of uselessness or excessive or inappropriate guilt (which can be delusional) almost every day (not just self-blame or guilt about being sick).

8. Decreased ability to think or concentrate or indecision, almost every day (indicated either by personal story or observed by other people).

9. Recurrent thoughts of death (not just fear of death), recurrent suicidal ideation without a specific plan or suicide attempt or a specific plan for committing suicide.

B. Symptoms cause clinically significant distress or impairment in the social, occupational, or other important areas of functioning.

C. The episode cannot be attributed to the physiological effects of a substance or a medical condition.

We consider that the patient meets criterion 2, given that he has episodes when he does not leave the house for a period of time, when he no longer takes part in any social environment, which he says, moreover, that he lacks, that he needs a group and that he needs to be recognized for his merits. Moreover, the patient says that he sleeps all day and that he would like to stop doing that and that he has almost no activities.

We also consider that the patient meets criterion 4, because he complains of sleep problems, that he would like to sleep more, that the treatment gives him nightmares, but also that he had a period of 5 days in which he could not sleep.

We consider that the patient also meets criterion 7 , guilt seeming to be a prevalent feeling in him, often excessive, inadequate, maybe even delusional. The patient declares that he apologized to God, because he would have hurt himself by not taking care of himself. The patient also remembered a moment in his childhood when he stole a piece of gum. He says that he received unemployment benefits in Denmark and then told the authorities there that he did not meet all the conditions of the aid and tried to reimburse an amount of money that he did not consider appropriate. He 
says he wants to end things with Denmark, to be "clean." The client also seems to feel guilty about certain acts in adolescence, before approaching God, as he declares.

In addition, we consider criterion 8 to be met, as the patient complains of concentration problems while studying in Denmark.

In conclusion, we believe that the criteria for a recurrent short-term depressive disorder are met. The patient seems to have episodes of depression, somewhere psychotic elements do appear, such as the one in which he says he was talking to God, that he told him to leave a key in the grass and guided him on the way to church, where the patient went naked.

\subsection{DIFFERENTIAL DIAGNOSIS}

\section{Bipolar Disorder II}

In order to be diagnosed with a bipolar disorder, the patient would also need to meet diagnostic criteria for a manic or hypomanic episode. The criteria for the hypomanic episode in DSM-5 are as follows:

A. A well-defined period, characterized by abnormally and persistently euphoric, expansive or irritable mood and by an abnormally and persistently high level of activity and energy, lasting at least four consecutive days and present most of the day, almost daily.

B. During mood swings and increased energy or activity, three (or more) of the following symptoms (four if the mood is only irritable) persisted, represent a significant change from normal behaviour, and are present at a significant level:

1. Exaggerated self-esteem or a sense of grandeur

2. Decreased need for sleep (e.g., the individual feels rested after only three hours of sleep).

3. The individual is more talkative than usual or has the pressure to speak

4. Running away from ideas or the subjective feeling of accelerating thinking

5. Distractibility (i.e., attention is easily captured by unimportant or irrelevant external stimuli), reported by the patient, or observed by the entourage.

6. Increasing activity aimed at a goal (either social, at work or school, or sexual) or psychomotor agitation.

7. Excessive involvements in activities with high potential to lead to unpleasant consequences (e.g., engaging in very expensive entertainment, inappropriate sexual behaviour, or reckless investment in business).

C. The episode is associated with an unequivocal change in functioning, which is not characteristic of the individual when it is not symptomatic.

D. The alteration of the disposition and the modification of the operation are observed by the people around.

E. The episode is not severe enough to cause a marked deficit in social and professional functioning or to require hospitalization. If psychotic elements are present, the episode is, by definition, manic. 
F. The episode cannot be attributed to the physiological effects of a substance (e.g., an abuse drug, a drug, another treatment).

We consider that the patient does not meet three or more criteria from criterion B. He does not show exaggerated self-esteem or feelings of grandeur, seeming, on the contrary, modest, often attributing his successes to situational factors. He says, for example, that they learned Danish faster than the others did, but that is because for the ones the language was harder, as they came from other continents.

The client also says that he sleeps a lot, sometimes and that he would like to sleep more, so the B2 criterion is not met either. For criterion B3, the customer seems quite talkative, but we do not think he would be more talkative than usual; saying that he also worked in sales and that he had to talk a lot with people, and this could characterize him.

The patient meets criterion B4, which has a disorganized discourse, and the flight of ideas is evident in it. The patient does not seem to meet criterion B5, and for criterion B6, we do not notice an increase in activity, although he has periods in which he works and does it successfully, but it does not seem an even exacerbated activity, outside the spectrum of work attributions.

In connection with criterion B7, the patient makes an unsuccessful investment at some point, but it is possible that this failure is caused by the environmental situation (the global financial crisis that occurred at that time), not a reckless investment.

\section{Obsessive Compulsive Disorder}

In a discussion with colleagues, a possible diagnosis of obsessive-compulsive disorder was discussed, but criterion A from DSM-5, which we present below, of this disorder does not seem to be met by the patient:

A.Presence of obsessions, compulsions, or both:

Obsessions are defined by (1) and (2):

1. Recurrent and persistent thoughts, impulses or images, which are felt, at some point during the disturbance, as intrusive and unwanted, and which for most individuals cause marked anxiety or discomfort.

2. The individual tries to ignore or suppress such thoughts, impulses or images or to neutralize them by another thought or action (i.e., by performing a compulsion). The patient does not complain of recurrent and persistent, intrusive and unwanted thoughts, impulses or images. Also, do not try to ignore or suppress such thoughts, etc.

\section{Schizophrenia}

In a discussion with colleagues, a possible diagnosis of schizophrenia was also discussed. We present below the diagnostic criteria for schizophrenia.

A. Two (or more) of the following criteria, each lasting significantly over a period of one month (or less if the treatment was effective). At least one of them must be (1), (2) or (3):

1. Delusional ideation 


\section{Hallucinations}

3. Disorganized speech (e g , frequent derailment or inconsistency

4. Intense disorganized or catatonic motor behaviour

5. Negative symptoms (i e, decreased expression of emotions or abolition

B. Each episode of the disorder lasts at least one month, but less than 6 months. If the diagnosis needs to be made before recovery, it will be referred to as "provisional".

C. Schizoaffective disorder and depressive or bipolar disorder with psychotic symptoms were excluded because: either 1) no major or manic-depressive episode occurred simultaneously with the active phase symptoms, or 2) if affective episodes occurred simultaneously with the active phase symptoms, they had a very short duration compared to the total duration of the active and residual periods of the disease.

D. The disorder cannot be attributed to the physiological effects of a substance (e.g., a drug of abuse, a drug) or to medical conditions.

The patient seems to have delusional ideas of guilt (criterion A1), he seems to have an episode in which he had hallucinations (criterion A2), declaring that God communicated with him. But these symptoms do not seem to last long enough to be met as diagnostic criteria for schizophrenia. When asked, the patient states that he did not perceive "voices," but thoughts that were somehow joined by his authentic thoughts.

The patient appears to have disorganized speech (criterion A3). One of the colleagues theorized a possible catatonic episode of the patient (criterion A4), and criterion A5 seems to have been met only during several years in which the patient to express less and less emotions.

In addition, we do not consider criteria $B$ and $C$ to be met.

Dr. Trifu also brings a counterargument for the diagnosis of schizophrenia, saying that this patient has a high functioning after the first hospitalization, without taking any treatment.

\section{Schizoaffective disorder - Depressive type}

The DSM-5 criteria for schizoaffective disorder are as follows:

A. A continuous period of illness during which a major affective episode (major depressive or manic) occurs simultaneously with Criterion A of schizophrenia.

Note: The major depressive episode must include Criterion A1: Depressive mood.

B. Delusional ideas or hallucinations present for at least 2 weeks, in the absence of a major affective episode (depressive or manic), at any time during the illness, throughout life.

C. Symptoms that meet the criteria for a major affective episode are present most of the time during the active and residual phases of the disease.

D. The disorder cannot be attributed to the effects of a substance (e.g., a drug of abuse, a drug) or medical conditions.

The psychotic elements (hallucinations) of the patient seem to occur at a time when he feels a lot of guilt, which is a feeling that seems predominant in the patient's 
life. The patient's mood seems to be depressive in many instances. We consider criterion A to be met, but some of the symptoms of schizophrenia seem to develop over time, not to be present from the beginning of the mental illness.

The patient presents with delusional guilt and paranoid ideas, which seem to occur outside of major emotional episodes. Thus, criterion B could be met. Also, the affective symptoms seem to be present more than those of schizophrenia, so criterion $\mathrm{C}$ can be met. We consider criterion $\mathrm{D}$ to be fulfilled, as the patient does not seem to have a history of substance abuse or medical conditions leading to the development these mental illnesses.

The patient seems to have some recurrent depressive episodes first, and over time, over the years, to develop symptoms that make it possible to be included in the schizoaffective disorder.

\section{Schizotypal personality disorder}

A diagnosis of schizotypal personality disorder for the patient was also discussed. Below are the diagnostic criteria:

A. A pervasive pattern characterized by poor social and interpersonal relationships, marked by acute discomfort and reduced ability to develop close relationships, as well as cognitive and perceptual distortions and eccentric behaviour, which begins in young adulthood, manifests itself in various situations and meets five (or more) of the following criteria:

1. Reference ideas (excluding delusional reference ideas

2. Bizarre beliefs or magical thinking, which influence behaviour and disagree with cultural norms (e.g., belief in superstitions, clairvoyance, telepathy, or "sixth sense"; in children and adolescents there may be strange fantasies and concerns).

3. Unusual perceptual experiences, including bodily illusions

4. Bizarre thinking and language (e g, vague, circumstantial, overworked or stereotypical speech

5. Suspicious character or paranoid ideation

6. Inadequate or limited feelings

7. Bizarre, eccentric, strange behaviour, or appearance

8. Lack of close friends and confidants, except for first-degree relatives

9. Excessive social anxiety that is not reduced by accommodating to the environment and tends to be associated with paranoid fears rather than negative selfesteem.

B. These manifestations do not occur exclusively in schizophrenia, bipolar or depressive disorder with psychotic symptoms, another psychotic disorder or autism spectrum disorders.

Criterion A2, although it seems to be met by the patient, can be attributed to the family environment in which he grew up, his family having the same beliefs, so the patient is in agreement with the environment from which he comes. 
Criterion A5 seems to be met, the patient sometimes having a paranoid ideation. Also, his emotionality seems to be limited, so the A6 criterion can be met. Criterion A8 also seems to be met, except that he is in a relationship with a woman. Given that 5 diagnostic criteria A should be met, we consider that the patient does not suffer from this personality disorder

\section{CONCLUSIONS AND RECOMMENDATIONS}

\subsection{PSYCHODYNAMIC INTERPRETATION}

The patient has a disorganized speech, there are delusional ideas, he starts from an idea and very easily moves away from it. This symptom is called incontinence or speech pressure. It is a galloping thinking, with an increased rhythm of associations. He seems to have a thought disorder, this flight of ideas and his own theme, which takes him out of the current reality. He has a fragmentary delusional idea of guilt and persecution. We identify concerns of prevalent intensity in the area of guilt. One can also identify in the speech a tendency towards regression or the creation of an innocent profile. Freud et al. (2009)

He is also unaware of a possible trigger (or associated event), which is his sister's diagnosed skin cancer. In addition, the patient is in denial, although over time it has evolved, from denying any psychological or psychiatric component in what is happening to him. Awareness of the trauma caused by his sister's illness could be a solution to an important aspect of his condition. But he declares that he does not have such mechanisms and that he is a strong man.

There is the possibility of a punitive Superego, developed by oneself, due to the lack of a Superego, his father being in prison during the patient's childhood. This can be a trauma for the patient, who is being teased at school due to his father's detention. The patient seems to be looking to build a superego, from the age of 5-6 wanting to go to church, looking for the representation of an authority, a parent, something to take care of him. Akhtar (2017)

In addition, an inferiority complex of the patient is highlighted, caused by the same detention of the father and perpetuated over time, including in his last love affair, in which the wife also laughs at his family of origin. The whole family of the patient's origin seems to have a sensitivity in the skin area, all looking to receive light / heat / affection, from a light bulb bought on the internet, not receiving it from elsewhere.

The patient could have suffered a traumatic experience in the relationship with the girl who had two abortions with him, he has already built a rather rigid self, which could have made him live these experiences quite hard, and being able to -it leads him to depression and, over time, to very strong ideas of guilt. Grinberg (1992)

We notice the hypostasis of a man with problems with sexual dynamics, but these problems being a rationalization of the fact that he did not want to have sex, because this made him feel guilty. He rationalized this by saying that it was a sin to have sex before marriage, but he did not even take any steps towards a marriage with the 
woman he was in a relationship with. Due to a severe superego, the patient seems to adopt an ascetic path, which protects him from guilt and causes him problems with sexual dynamics.

\subsection{PATIENT VULNERABILITY}

- the patient's sister suffers from a rather serious type of cancer

- the patient's life partner is still trying to help him, but for a good period of time she fails in doing so and no progress appears

- he fails to function socially

- delusional ideas of persecution, guilt, mistrust

\subsection{POSITIVE PROGNOSIS FACTORS}

- support from his sister

- support from his life partner, who wants to help him heal and seems to do everything possible for it

- therapeutic alliance

- the fact that he goes to therapy and continues to take psychiatric treatment

\subsection{NEGATIVE PROGNOSIS FACTORS}

- denial of the possible trigger event in his life - his sister's illness

- lack of awareness of certain links between life events and his mental impairment

- lack of progress in terms of social and sexual functioning

\section{REFERENCES}

Akhtar, S. (2017). Mistrust, Suspicions And Paranoia In Adulthood. In Mistrust: Developmental, Cultural And Clinical Realms (pp. 41-58). Karnac Books.

Diagnostic And Statistical Manual Of Mental Disorders. (2014). American Psychiatric Association.

Freud, S., Nevroză, Psihoză, Perversiune, E., Trei, B., \& Gabbard, G. O. (2009). Psychodynamic Psychiatry In Clinical Practice., 7.

Grinberg, L. (1992). Guilt And Depression. London: Karnac Books.

ICD-10: International Statistical Classification Of Diseases And Related Health Problems: Tenth Revision. (2004). World Health Organization.

Trifu, S. (2016). Diagnostic Procedural Diagram In Medical Psychiatric Approach. Saarbrucken: LAP Lambert Academic Publishing.

Vandenbos, G., \& R. (2015). APA Dictionary Of Psychology. Washington, DC: American Psychological Association. 